\title{
EFICÁCIA DA INTERVENÇÃO FONOAUDIOLÓGICA PARA ATENUAR O ENVELHECIMENTO FACIAL
}

\section{Effectiveness of speech therapy intervention for mitigating facial aging}

\author{
Yasmin Frazão ${ }^{(1)}$, Silvia Bertacci Manzi (2)
}

\begin{abstract}
RESUMO
Tema: eficácia da intervenção fonoaudiológica na estética facial para atenuar os sinais de envelhecimento. Procedimentos: análise fotográfica e descrição do raciocínio clínico utilizado em três casos clínicos de clientes do sexo feminino, com queixas referentes à estética facial, que se submeteram ao atendimento fonoaudiológico. Foram realizadas a entrevista inicial, a avaliação das funções estomatognáticas, a avaliação da movimentação dos músculos da mímica expressiva e a documentação fotográfica e em vídeo. Com base nessa avaliação e na queixa das clientes foram estabelecidas as metas terapêuticas. Em cada um dos casos foi proposto um raciocínio clínico especifico e individualizado, levando-se em consideração a sinergia muscular e a presença ou ausência de flacidez de pele. Durante doze sessões, com duração de 50 minutos, foram feitos exercícios musculares funcionais e massagens na face. As clientes foram orientadas a manter uma rotina diária de procedimentos em casa. Resultados: após o atendimento fonoaudiológico pode-se observar que os sinais de envelhecimento foram atenuados, sendo esse resultado compatível às expectativas das clientes, que expressaram satisfação ao final do atendimento. Conclusão: constatou-se a eficácia da intervenção fonoaudiológica, por meio da documentação fotográfica, como resultado da aplicação de um raciocínio clínico individualizado, específico da área de motricidade orofacial com enfoque em estética.
\end{abstract}

DESCRITORES: Fonoterapia; Estética; Rejuvenescimento

\section{INTRODUÇÃO}

Os sinais inerentes ao envelhecimento podem ser causados por um processo natural - o envelhecimento intrínseco - ou por fatores externos - o enveIhecimento extrínseco ou fotoenvelhecimento ${ }^{1,2}$.

O envelhecimento intrínseco é conseqüência do desgaste natural do organismo e independe de fatores externos, apesar de ser altamente influenciado por eles ${ }^{2,3}$. São alterações clínicas, histológicas e fisiológicas que ocorrem na pele e músculos no processo de envelhecimento, tais como, perda de gordura, colágeno, elastina, flacidez de pele e de músculo ${ }^{1,3}$. A hereditariedade é outro fator que tem forte influência no envelhecimento. ${ }^{1}$

(1) Fonoaudióloga; Mestre em Distúrbios da Comunicação pela Pontifícia Universidade Católica de São Paulo, PUC/ $\mathrm{SP}$,

(2) Fonoaudióloga; Especialista em Motricidade Orofacial pelo CRFa /CEFAC - Saúde e Educação de São Paulo, São Paulo,

Conflito de interesses: inexistente
O comportamento muscular também se altera com o envelhecimento concorrendo para o aparecimento de rugas. Como exemplo, podemos citar a perda da acuidade visual que somada ao excesso de pele em pálpebra superior e ptose do supercílio resultam da contração exacerbada dos corrugadores e do músculo frontal, respectivamente ${ }^{4}$.

O envelhecimento extrínseco é aquele causado por fatores ambientais, principalmente a radiação ultra-violeta (UV) - por isso também é chamado de fotoenvelhecimento. Outros fatores, como o tabagismo, o estilo de vida, a alimentação, o peso, o estresse, privação de sono ${ }^{2,3}$, também corroboram com esse processo.

Os diferentes tipos faciais apresentam condições musculares distintas de acordo com suas características esqueléticas, resultando em adaptações ou alterações funcionais orofaciais ${ }^{5,6}$. Assim, na face curta, o terço inferior é reduzido e a musculatura é forte, especialmente os masseteres ${ }^{5,6}$. Há predominância de alta força de mordida ${ }^{6}$ e maior possibilidade de presença de rugas em região perioral, pela 
tendência ao apertamento da musculatura facial na fala, na pausa durante a fala e na deglutição. Já na face longa, o terço inferior é aumentado, a musculatura em geral é mais débil e estirada, com baixa força de mordida ${ }^{6}$ e menor possibilidade de se observar a presença de rugas, porém com maior tendência à flacidez facial. Nos tipos classe II e III (padrões faciais ântero-posteriores), pelas características ósseas e musculares que apresentam, ocorrem várias adaptações funcionais 5,6, como alterações na mastigação, hiperfunção de mentual, posição inadequada e/ou diminuição na força de ejeção da língua na deglutição, redução da contração dos supra-hióideos na deglutição, flexão ou extensão acentuada da cabeça. Com essas adaptações, são frequentes as compensações musculares, que interferem diretamente na simetria e harmonia facial, sendo maior a possibilidade de aparecimento de rugas e sinais de envelhecimento.

Deve-se considerar, também, a participação do sistema músculo-aponeurótico superficial (SMAS) nas expressões faciais. Descrito em 1974 por Mitz e Peyronic, como uma complexa unidade morfológica que divide o tecido subcutâneo em duas camadas, essa estrutura pode ser definida como uma camada fibromuscular que interconecta os músculos miméticos da face e a pele, sendo contínua com o platisma ${ }^{7,8}$. Ela se estende da região malar para o terço superior da face, tornando-se contínua à galéa, para o terço inferior torna-se parte do platisma e, lateralmente, no terço médio, se interdigita à fascia da parótida (sobre a glândula parótida) 9,10.

Sua função é amplificar as contrações dos músculos nas expressões faciais, ou seja, age como um distribuidor das contrações dos músculos da face para a pele ${ }^{11,12}$. Justifica-se assim, o raciocínio clínico de se realizar uma intervenção em grupos musculares correlacionados e não somente no músculo sobre o qual a ruga está localizada, tendo-se em vista que "cada expressão é a resultante da ação de vários músculos, transmitida à pele pelo SMAS" 11.

Além da morfologia, deve-se considerar as especificidades neurofisiológicas dos músculos da face ao se escolher os recursos técnicos a serem utilizados no atendimento fonoaudiológico.

A contração dos músculos da face é dada por via motora voluntária (sistema piramidal), por via motora involuntária (sistema exatrapiramidal) e por via cerebelar, que controla o sinergismo e harmonia dos movimentos ${ }^{13}$. De acordo com proposta fonoaudiológica aqui apresentada, no inicio do processo terapêutico, as expressões faciais e demais funções orofaciais devem ser executadas de forma correta, voluntariamente e repetidas várias vezes ao dia, para que se tornem involuntárias. Assim, um sorriso em que há contração exagerada de zigomáticos e orbicular dos olhos, com formação de rugas periorbitárias, será modificado para a atenuação das mesmas, primeiramente com a contração voluntária dos músculos (via piramidal) e, posteriormente, com contração involuntária (via extra-piramidal), se o novo padrão motor for automatizado através da repetição sistemática.

A Fonoaudiologia Estética da Face é uma área que situa-se entre outras relacionadas diretamente com a Estética, como a Odontologia, a Dermatologia, a Nutrição, a Endocrinologia e a Cirurgia Plástica e que têm em comum o objetivo de atenuar o processo de envelhecimento.

Com uma proposta não invasiva, a Fonoaudiologia Estética da Face tem por objetivo atenuar os sinais de envelhecimento, promovendo harmonia facial. Na intervenção terapêutica, o fonoaudiólogo atua nos músculos envolvidos na formação de cada ruga, respeitando a correlação entre os grupos musculares dos terços da face, reorganizando a dinâmica da mímica facial e adequando as funções de mastigação, de deglutição e de fala. Técnicas de conscientização, exercícios musculares, alongamentos e massagens na face têm por finalidade diminuir a intensidade, a frequência e a duração da contração muscular nas diversas situações em que ela ocorre. Por meio dessa intervenção, alcança-se a reorganização dos grupos musculares utilizados na comunicação e nas funções estomatognáticas. Atua-se em três aspectos: na função ${ }^{14,15}$ (reorganizando a mímica e adequando as funções estomatognáticas); na pele (indiretamente, favorecendo a vascularização e a tonificação); nos músculos (adequando a contração e promovendo alongamento). Como resultado, obtém-se suavização de rugas e marcas de expressão e a melhora na definição de contornos que contribuem para o rejuvenescimento do rosto.

Apesar de recente, a atuação fonoaudiológica em estética facial ganhou maior projeção, nos últimos dez anos, com a publicação de trabalhos de profissionais que atuam na área de Motricidade Orofacial com enfoque em estética ${ }^{11,16-20}$. O número de publicações é reduzido e, na sua maioria, contém uma descrição genérica dos diversos recursos técnicos e dos objetivos a serem alcançados, porém o raciocínio clínico é pouco discutido.

Tendo-se como base a intervenção fonoaudiológica citada acima, pretende-se verificar sua eficácia para atenuar os sinais de envelhecimento, por meio da documentação fotográfica e complementar as discussões publicadas na área, descrevendo o raciocínio clínico, em cada um dos três terços da face. 


\section{APRESENTAÇÃO DOS CASOS}

O presente artigo é um estudo longitudinal e constitui-se da apresentação de fotografias, pré e pós atendimento fonoaudiológico, de terços da face de três mulheres, com idades de 41, 48 e 49 anos. Será apresentado, também, o raciocínio clínico utilizado em cada caso.

Como critério de inclusão as clientes não poderiam ter alterações estéticas decorrentes de lesão neurológica central, periférica ou de síndromes com alterações anatômicas faciais.

Para o atendimento, foi realizada uma avaliação fonoaudiológica que constou de: entrevista inicial, aplicação do protocolo de avaliação proposto por Pierotti ${ }^{21}$, filmagem das funções de mastigação e deglutição de líquido (água) e sólido (pão francês), filmagem da mímica facial em situação de fala espontânea e na realização de movimentos específicos, quando foi solicitada a contração dos diversos grupos musculares e a execução de algumas expressões faciais (surpresa, mau cheiro, braveza, sorriso), documentação fotográfica padronizada nas posições frente, perfil direito e esquerdo, meio perfil $\left(45^{\circ}\right)$ direito e esquerdo - pré e pós atendimento. O tripé foi posicionado a $90 \mathrm{~cm}$ de distancia das clientes. As fotografias foram realizadas com câmera digital Casio Exlim (foto do terço médiocliente atendida em consultório particular) e câmera Canon Rebel XT, lente de $35 \mathrm{~mm}$ (fotos dos terços superior e inferior - clientes atendidas no Ambulatório de Motricidade Orofacial com enfoque em estética, coordenado por Silvia Pierotti, no Instituto CEFAC-Saúde e Educação-SP), em sala padronizada com luminosidade controlada. A posição da cabeça foi estabelecida a partir do controle do olhar num ponto fixo nas paredes da sala, feitas a $10 \mathrm{~cm}$ abaixo da estatura da cliente e pelo traçado de uma linha imaginária do tragus até o nasio.

As clientes foram atendidas em 12 sessões de 50 minutos, semanalmente, e mantinham uma rotina diária de procedimentos a serem realizados em casa. As fotografias dos terços foram selecionadas a partir da queixa principal das clientes: Caso 1 - contração exagerada do frontal; Caso 2 assimetria dos olhos e ptose palpebral; Caso 3 ptose e rugas nas bochechas.

O critério utilizado para interpretar a documentação fotográfica, pré e pós tratamento, foi descritivo-qualitativo, graduando as rugas e sinais de envelhecimento numa escala de 0 a 3 , em que (3) é a presença severa, (2) a moderada, (1) a leve, (0) ausência de rugas e sinais de envelhecimento.

As clientes responderam com SIM ou NÃO à uma única pergunta referente à sua satisfação com os resultados do tratamento.
A presente pesquisa foi aprovada pelo Comitê de Ética em Pesquisa do Centro de Especialização em Fonoaudiologia Clínica, sob número 002/2010.

\section{RESULTADOS}

A partir da avaliação de cada caso, foi estabelecido um plano de atendimento individualizado. Os casos atendidos aderiram ao trabalho proposto, foram assíduos e não tiveram dificuldades em executar as orientações que deveriam ser realizadas em casa. Devido à importância da repetição para a automatização de novos padrões motores, as expressões faciais e demais funções orofaciais foram executadas de forma correta, voluntariamente várias vezes ao dia, para que se tornassem involuntárias. A intervenção foi feita não somente nos músculos que estão localizados em cada terço, mas também, nos que a eles estão correlacionados favorecendo um equilíbrio no dinamismo muscular entre os terços. Apenas o terço relacionado à queixa principal da face de cada cliente será apresentado e discutido, porém todas receberam tratamento completo em toda a face.

Caso 1: Cliente do sexo feminino, de 41 anos de idade. $\mathrm{Na}$ avaliação fonoaudiológica constatouse que a contração dos músculos do terço superior era mais freqüente durante a fala em situações de ansiedade e inibição. Observou-se contração excessiva na porção frontal do occipitofrontal, com rugas estáticas e dinâmicas na testa (Figura 1); contração excessiva em músculos corrugadores, com rugas dinâmicas; reduzida contração do palpebral e reduzida contração excêntrica do orbicular dos olhos. A cliente apresentava tremor vocal, fala monotonal, reduzida amplitude de movimento de lábios e de mandíbula, comprometendo a inteligibilidade de fala. A mímica facial observada apresentava correlação com o estado emocional ${ }^{13}$ (ansiedade ao se comunicar) e com a morfologia facial (face curta, com tensão em terço inferior refletida em toda a face $)^{6}$.

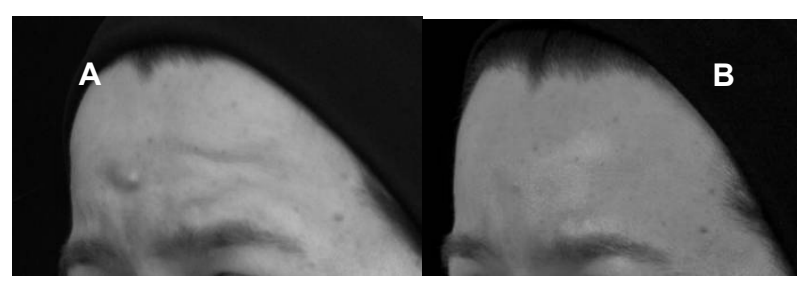

A-Pré-tratamento: (3) presença severa de rugas e sinais de envelhecimento

B-Pós- tratamento: (1) presença leve de rugas e sinais de envelhecimento

Figura 1 - Caso 1: Meio perfil em repouso 
Ao término do processo terapêutico, a cliente demonstrou satisfação com os resultados alcançados. Houve diminuição acentuada da contração do frontal ao falar (Figura 2); maior conscientização das situações de ansiedade com consequente domínio sobre contração dos músculos do terço superior (Figura1).

Caso 2: Cliente do sexo feminino, de 48 anos de idade. $\mathrm{Na}$ avaliação observou-se contração do orbicular dos olhos na comunicação, com formação de rugas periorbitárias; contração do frontal, com elevação da sobrancelha esquerda, por hábito expressivo desde a juventude e para compensar a ptose do músculo orbicular do olho e palpebral, resultando em assimetria dos olhos; presença de bolsas em pálpebras inferiores. Esses sinais observados em terço médio foram causados tanto por hábitos inadequados como pelo envelhecimento intrínseco ${ }^{1,2,22}$, levando à flacidez de pele e de músculo.

Ao final do atendimento, os olhos estavam mais simétricos, houve redução de movimentação exagerada em frontal na comunicação e redução das bolsas em pálpebra inferior (Figura 2). Estes resultados estavam de acordo com as expectativas da cliente (Figura 2).

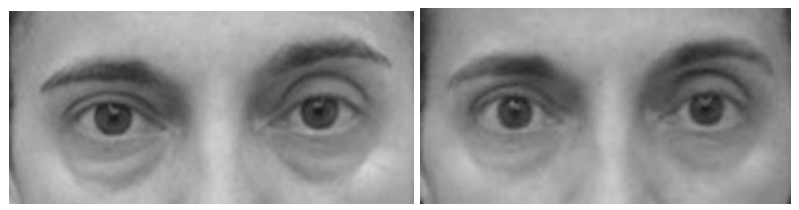

A-Pré-tratamento:(2) presença moderada de rugas e sinais de envelhecimento

B-Pós-tratamento: (1) presença leve de rugas e sinais de envelhecimento

Figura 2 - Caso 2: frente em repouso

Caso 3: Cliente do sexo feminino, de 49 anos de idade. $\mathrm{Na}$ avaliação observou-se contração exagerada de orbiculares dos lábios: na deglutição de saliva, de alimentos sólidos e líquidos, compensando posição inadequada de língua; nas pausas da fala, por hábito, associada à contração acentuada de depressores de lábio inferior, ângulo da boca e mentual. Apresentava mastigação predominantemente do lado direito por perda de peças dentárias do lado esquerdo; tensão aumentada em mentual, com formação de sulco, na fala e ao deglutir. Havia presença de rugas malares dinâmicas e estáticas (2 à direita e 5 à esquerda); rugas dinâmicas superiores e inferiores nos lábios; sulco nasogeniano à direita e à esquerda; lado direito da face com tônus aumentado e esquerdo diminuído; lábios com cantos caídos ao falar, principalmente; lábios ressecados e assimétricos, com lábios superior e inferior direito mais grossos, comissura direita mais alta em repouso e em sorriso aberto e fechado. As rugas em terço inferior eram causadas tanto pelos hábitos inadequados de deglutição, quanto pela flacidez de pele e músculos inerentes ao envelhecimento.

Ao final do atendimento, observou-se que houve redução da tensão em terço inferior, diminuição das rugas malares, adequação da mastigação e deglutição, melhora do contorno facial e redução da mímica facial exagerada na comunicação, tendo a cliente ficado satisfeita com os resultados (Figura 3).

As três clientes ficaram satisfeitas com os resultados obtidos com o tratamento fonoaudiológico e observaram melhoras na estética facial.

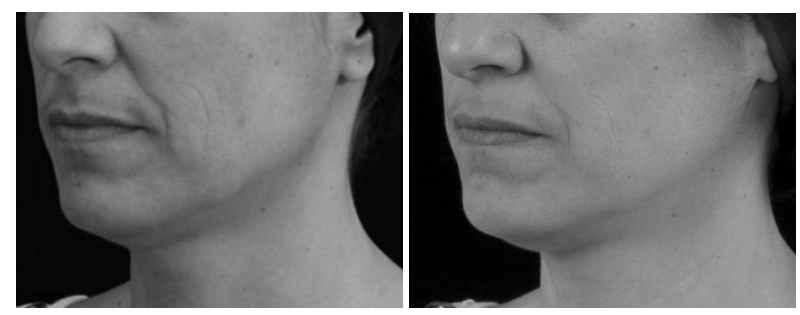

A-Pré-tratamento:(3) presença severa de rugas e sinais de envelhecimento

B-Pós-tratamento: (1) presença leve de rugas e sinais de envelhecimento

Figura 3 - Caso 3: meio perfil em repouso

\section{DISCUSSÃO}

Na prática clínica, observamos que as mudanças nos padrões motores relacionados à mímica facial e funções estomatognáticas, uma vez aprendidos e integrados à rotina diária do paciente, se mantém sem a necessidade de repetição diária de exercícios específicos. Porém, é necessária uma constante manutenção/ atenção com a formação de rugas resultantes de aspectos que são inerentes ao processo contínuo do envelhecimento, tais como, perda de fibras musculares, diminuição de colágeno, de elastina e de gordura ${ }^{3}$. Sendo assim, as massagens na face e em pescoço, os exercícios isométricos em olhos, excitação da porção frontal do occipitofrontal, exercícios isométricos e isotônicos em bucinador, em supra-hióideos e língua devem ser mantidos, dependendo dos objetivos a serem alcançados em cada caso. 
Deve-se adequar os exercícios respeitando, "as características das fibras musculares e o potencial de resistência à fadiga muscular que os músculos orofaciais apresentam" ${ }^{23}$. Suas unidades motoras são pequenas, o que garante a precisão funcional dos mesmos ${ }^{13,23,24}$. Seu tamanho, forma e grau de desenvolvimento dependem, entre outras coisas, de idade, dentição e sexo ${ }^{25}$. São músculos curtos e dificilmente podem ser isolados uns dos outros na realização das manobras de reabilitação, na mímica facial e nas funções orofaciais ${ }^{11}$.

No atendimento dos casos citados, quando foram solicitados exercícios para os músculos da face, foi dada atenção aos possíveis tremores e compensações musculares que indicavam fadiga. As massagens e alongamento nos músculos da face sempre precediam os exercícios isométricos e isotônicos, como forma de preparo das fibras musculares para uma contração funcional desejada. Outro recurso técnico utilizado foi a colocação de Transpore ${ }^{\mathrm{MR}}$ para minimizar as compensações e contrações exageradas da mímica facial.

O conhecimento da correlação entre os grupos musculares é de fundamental importância na atuação fonoaudiológica para nortear o raciocínio clínico que deve ser específico e individualizado.

\section{TERÇO SUPERIOR - Caso 1}

No terço superior da face encontram-se as fibras do músculo frontal que, por não possuírem origem óssea, se interdigitam inferiormente com os outros músculos que fazem parte deste terço, a saber, o músculo prócero, na região do násio, os músculos corrugadores, na região medial dos supercílios e mais lateralmente, com as fibras do músculo orbicular dos olhos, que fazem parte do terço médio ${ }^{26}$

No Caso 1 (Figura 1) atuamos nos seguintes grupos musculares para atenuar a contração exagerada dos músculos do terço superior:

- Porção frontal do occipitofrontal: soltura e excitação desse músculo para manutenção de contração funcional, suficiente para evitar a queda das sobrancelhas e a formação de rugas; aumento da informação sensorial tátil (uso do Transpore ${ }^{\mathrm{MR}}$ ) preconizado por Pierotti, e conscientização da contração exagerada nos estados emocionais de ansiedade, para inibir a mobilidade inadequada na mímica facial, inicialmente, com controle voluntário.

- Corrugadores: nesses músculos foi aplicada a mesma intervenção utilizada para a porção frontal do occipitofrontal, excluindo a excitação muscular, tendo-se em vista que o objetivo é reduzir sua contração.

- Orbiculares dos olhos e palpebrais: apesar de fazerem parte do terço médio, foram realizados exercícios isotônicos e isométricos e massagens, como forma de equilibrar o dinamismo muscular entre os músculos do terço superior $\mathrm{e}$ médio da face, promovendo maior abertura dos olhos principalmente em situações de comunicação, com redução da contração do frontal e corrugadores.

Neste caso, para que houvesse mudança na mímica facial, trabalhou-se a adequação da entonação vocal e da amplitude dos movimentos articulatórios, reduzindo a contração exagerada dos músculos do terço superior durante a comunicação, transferindo a ênfase expressa na mímica facial para a voz.

\section{TERÇO MÉDIO - Caso 2}

No terço médio, estão localizados os músculos orbicular do olho, levantador da pálpebra superior, levantador do lábio superior e da asa do nariz, levantador do lábio superior, zigomático maior e menor (origem e porção média) ${ }^{13,25}$. Desses músculos, os zigomáticos maior e menor, o levantador do lábio superior e da asa do nariz e o levantador do lábio superior possuem inserção óssea direta ${ }^{11,25,26}$.

No Caso 2 (Figura 2), a partir da avaliação, foram trabalhados os seguintes grupos musculares para a obtenção de simetria dos olhos, redução de bolsas em pálpebra inferior:

- Orbicular dos olhos: massagens para aumento da irrigação, drenagem, manutenção de maior abertura; alongamento; obtenção de abertura inibindo a contração da porção frontal do occipitofrontal.

- Palpebral: aumento da contração para manutenção de olhos mais abertos.

- Porção frontal do occipitofrontal: apesar deste não fazer parte deste terço foi feita excitação muscular para manutenção de contração funcional, suficiente para manter as sobrancelhas elevadas, com maior número de repetições à direita; aumento da informação sensorial tátil (uso do Transpore ${ }^{\mathrm{MR}}$ ) e conscientização da contração exagerada na comunicação, somente do lado esquerdo, para redução da movimentação deste lado favorecendo maior abertura do olho direito com conseqüente ganho de simetria.

Além do trabalho citado acima, houve a adequação do uso dos músculos da mímica facial durante a comunicação, evitando a exagerada elevação do frontal e favorecendo a abertura de olhos como forma de expressar-se.

\section{TERÇO INFERIOR - Caso 3}

No terço inferior, estão localizados os músculos abaixador do septo nasal e lábio superior, o risório, o bucinador, os zigomáticos maior e menor (inserção 
no orbicular da boca), orbicular da boca, abaixador do ângulo da boca e lábio inferior, levantador do ângulo da boca e o mentual. Os músculos do terço inferior da face e pescoço derivam do platisma primitivo, que não apresenta inserção óssea ${ }^{26}$.

No Caso 3 (Figura3) foram trabalhados os seguintes grupos musculares para atenuar as rugas malares, as periorais e obter melhor contorno facial:

- Músculos do terço inferior: alongamento para reduzir a tensão exagerada em toda a musculatura deste terço, como um pré requisito para reequilibrar as forças musculares da face.

- Bucinadores e zigomáticos - fortalecimento desses músculos para obter melhora do contorno facial, reduzindo a ptose das bochechas e as rugas aí localizadas (uso do exercitador facial) ${ }^{27}$. Aumento da informação sensorial tátil (uso do Transpore ${ }^{\mathrm{MR}}$ ) sobre modíolo, músculos depressores de lábio inferior e mentual, durante a terapia (apesar de ter sido orientada, cliente não usou o Transpore $^{\mathrm{MR}}$ diariamente em casa).

- favorecendo a conscientização da contração exagerada na comunicação e na deglutição, reorganizando a dinâmica muscular facial.

- Adequação do processo da deglutição, objetivando mastigação bilateral e posteriorizada e adequação da postura da língua na ejeção dos alimentos.

- Tonificação da pele e musculatura por meio de massagens.

Complementando o trabalho, buscou-se obter maior amplitude de movimento de lábios, língua e mandíbula em situações dinâmicas de comunicação, mantendo o alongamento conquistado através das massagens.

Conforme visto nos casos citados, pele e músculos participam na formação das rugas, que ocorrem sempre perpendicularmente à direção de contração do músculo e são mais ou menos pronunciadas de acordo com a frequência, a intensidade e a duração desta contração. Elas podem ser simétricas ou assimétricas dependendo da localização do grupo muscular que é mais intensamente usado na mímica ou função orofacial ${ }^{19}$. Para o prognóstico, deve-se levar em consideração algumas especificidades dos músculos e da pele.

No que se refere aos músculos, é primordial que se considere tanto o que é inerente ao próprio enveIhecimento - perda de massa muscular, declínio de força $a^{3,28-30}$ (Casos 2 e 3) como as condições musculares individuais - hipotonia, uso frequente e exagerado de um determinado grupo muscular (nos três casos apresentados) e compensações musculares (caso 2) $)^{11,15}$.

Com relação à pele, deve-se considerar para o prognóstico, que sua aparência harmoniosa é determinada por uma relação balanceada entre todas as estruturas que compõem a face (ossos, músculos, pele e seus componentes) ${ }^{11}$. Há interferência de fatores intrínsecos e extrínsecos, já citados anteriormente, levando à presença ou ausência de flacidez, à diminuição de colágeno, de gordura, de elastina e da hidratação da pele ${ }^{31}$.

No caso 1, o prognóstico é considerado favorável tendo-se em vista que a cliente não apresenta sinais de envelhecimento de pele, sendo necessário priorizar o trabalho muscular. No caso 2, evidencia-se flacidez de pele, com provável diminuição de colágeno, o que associado às suas condições musculares, agrava o prognóstico. No caso 3, além das características musculares já citadas, observa-se flacidez de pele, provável diminuição de colágeno e pele com pouca hidratação, fatores que são desfavoráveis para o prognóstico.

Nos três casos citados no presente artigo, observou-se um desequilíbrio na intensidade, na freqüência e na duração da contração nos grupos musculares e, em dois casos (2 e 3), observou-se, também, fatores intrínsecos de envelhecimento da pele que resultavam em rugas e sinais de envelhecimento. Mas, por meio das fotografias pós tratamento, fica evidente a melhora estética de todos os casos, obtida pela reorganização da dinâmica muscular facial nas diversas funções orofaciais. Resultados favoráveis também são encontrados em outros trabalhos da área ${ }^{19,20}$.

Devemos ressaltar que o fonoaudiólogo que atua em estética deve ter um raciocínio clínico especifico e individualizado, levando em conta a sinergia muscular e o processo de envelhecimento. Pensar na sinergia muscular significa intervir em grupos musculares que, nem sempre, estão diretamente causando as rugas e sinais de expressão. Isto é, não podemos intervir em um músculo isolado e sim em cadeias ou grupos musculares que atuam de forma integrada. Assim, trabalhamos no sentido de prevenir compensações buscando um equilíbrio muscular. $O$ fonoaudiólogo deve estar atento aos limites desse trabalho, observando que a condição muscular não é o único fator determinante na melhora da estética da face, pois a elasticidade e a tonicidade da pele são fatores de igual importância.

O envelhecimento é inexorável, sujeito a ação de fatores extrínsecos e intrínsecos. Essa ação pode ser de certa forma, controlada e atenuada com a reorganização muscular proposta pela Fonoaudiologia estética da face e a adoção de hábitos que levem a uma melhor qualidade de vida, a saber, uma alimentação equilibrada, a prática de exercícios físicos, o cuidado com a pele entre outros. 
Finalizando, acredita-se que muito ainda deve ser pesquisado nesse novo campo de atuação da fonoaudiologia, no sentido de ampliar os conhecimentos sobre as especificidades neurofisiológicas dos músculos faciais e da pele no processo de envelhecimento. Dessa forma, a escolha de recursos técnicos a serem utilizados será mais específica e eficaz, resultando em um atendimento mais pontual.

\section{CONCLUSÃO}

A eficácia da intervenção fonoaudiológica na estética facial foi comprovada pelo presente artigo, por meio da descrição do raciocínio clínico e de fotografias, pré e pós atendimento. Ressalta-se que a meta desta intervenção não é erradicar os sinais do envelhecimento, mas sim, atenuá-los e retardá-los.

\begin{abstract}
Background: effectiveness of Speech Therapy Intervention in facial aesthetics. Procedures: this effectiveness was evaluated through photographic analysis and clinical descriptions of three clinical cases concerning female clients with facial aesthetics complaints, who underwent the Speech Therapy Intervention - aesthetic treatment. An initial interview was carried out and assessments of both stomatognathic functions and muscle movements during speech were obtained. Photographic and video documentation on the client's facial features were made. Based on this evaluation and the client's demands, we set out therapeutic targets. In each case, a specific individualized clinical proposal was offered considering the muscular synergy and also the presence or absence of skin flaccidity. Muscular exercises and massages on the face were carried through during twelve 50-minutes sessions. The clients were asked to maintain a customized routine of these procedures at home on a daily basis. Results: after Speech Therapy Treatment, the signs of aging were noticeably mitigated. The results were successful by meeting the clients' expectations, and in addition, all clients reported being satisfied with the treatment. Conclusion: Speech Therapy Treatment's effectiveness was noticed through photographic and video documentation as the result of applying an individualized clinical proposal, specific for the orofacial motricity area, through an aesthetic emphasized focus.
\end{abstract}

KEYWORDS: Speech Therapy; Esthetics; Rejuvenation

\section{REFERÊNCIAS}

1. Borelli SS. Até 120 anos...Rejuvenescimento e cosmiatria. São Paulo: SENAC; 2008.

2. Souza SLG, Braganholo LP, Ávila ACM, Ferreira AS. Recursos Fisioterapêuticos Utilizados no Tratamento do Envelhecimento Facial. Revista Fafibe On Line, n.3, [periódico na Internet] ago.2007 [acesso em 10 de maio de 2010]. Disponível em: http://www.fafibe.br/revistaonline/arquivos/soraya recursos_fisioterapeuticos_envelhecimento_facial. pdf.

3. Oriá RB, Brito GAC, Ferreira FVA, Santana EN, Fernandes MR. Estudo das alterações relacionadas com a idade na pele humana, utilizando métodos de histo-morfometria e autofluorescência. An bras Dermatol. 2003; 78(4):425-34.

4. De Maio M, Magri IO, Bello CN. Toxina botulínica: a relação do tipo de paciente com a duração do efeito. Cirurgía Plástica Ibero-Latinoamericana. 2008; 34(1).
5. Ramires RR, Ferreira LP, Marchesan IQ. Tipologia facial aplicada à Fonoaudiologia: revisão de literatura. Rev Soc Bras Fonoaudiol. 2010; 15(1):140-5.

6. Daenecke S, Bianchini EMG, Silva A. Medidas antropométricas de comprimento de lábios superior e filtro. Pró-Fono R Atual Cient. 2006; 18(3): 249-58 7. Cruz JRS, Cruz AAV. Quantificação da ação do músculo frontal. Arq Bras Oftalmol 2004;67:237-40. 8. Ferreira LM, Hochman B, Locali RF, Rosa-Oliveira LMQ. A Stratigraphic Approach to the Superficial Musculoaponeurotic System and Its Anatomic Correlation with the Superficial Fascia. Aesth. Plast. Surg. 2006; 30:549-52.

9. De la Torre J, Garza RF, MD. Facelift Anatomy. Medscape from WebMD[periodico na Internet]. 2009Jan [acesso em 24 nov 2009];[aprox 4 pgs]. Disponível em: http://emedicine.medscape.com/ article/1294682-overview.

10. Schellini AS, Junior AAS. Suspensão subperiostal do terço médio da face: uma alternativa 
para correção do ectrópio cicatricial. Arq. Bras. Oftalmol. 2005; 68(4). 527-31.

11. Toledo PN. Fonoaudiologia e Estética: a motricidade orofacial aplicada na estética da face. São Paulo: Lovise; 2006

12. Larrabee WF, Makielski KH, Henderson JL. Surgical anatomy of the face. Google Livros[livros na Internet]. 2003 [acesso em julho 2009];195 páginas. Disponivel em: http://books.google.com.

13. Madeira MC. Anatomia da face: bases anátomofuncionais para a prática odontológica. 4. ed. São Paulo: Sarvier, 2003.

14. Oliveira AC, Anjos CAL, Silva EHAA, Menezes PL. Aspectos indicativos de envelhecimento facial precoce em respiradores orais adultos. Pró-Fono $\mathrm{R}$. Atual. Cient. 2007; 19(30).

15. Oncins MC, Freire R, Marchesan IQ. Mastigação: análise pela eletromiografia e eletrognatografia: seu uso na clínica fonoaudiológica. Distúrb Comum. 2006; 18(2): 155-65.

16. Pierotti $S$, Reis P. Terapia estética Muscular. In: Maio M.Tratado de Medicina Estética. São Paulo:Roca; 2004.3vol.p.1917-41.

17. Franco MZ. A Fonoaudiologia que Rejuvenesce. São Paulo: LivroPronto;2009.

18. Tasca SMT. Programa de aprimoramento muscular em fonoaudiologia estética facial (PAMFEF). Barueri: Pró-fono; 2002.

19. Takacs AP, Valdrighi V, Assencio-Ferreira VJ. Fonoaudiologia e estética: unidas a favor da beleza facial. Rev CEFAC 2002; 4:111-6

20. Paes C; Toledo PN; Silva HJ. Fonoaudiologia e estética facial: estudo de casos, Rev. CEFAC 2007; 9(2). 213-20.

21. Pierotti,S.Protocolo de Avaliação estética. In:Motricidade oral: como atuam os especialistas. Comitê de Motricidade oral - SBFa.Pulso:São José dos Campos;2004; anexo 3: 303-9.
22. Siqueira M, Joaquim A, Schellini AS, Padovani $\mathrm{CR}$, Cruz AAV. Alterações palpebrais após a idade de 50 anos. Arq Bras Oftalmol. 2005; 68(3):285-90. 23. Tessitore A, Pfelsticker LN, Paschoal JR. Aspectos neurofisiológicos da musculatura facial visando a reabilitação na paralisia facial. Rev CEFAC 2008;10(1): 68-75.

24. Coutrin GC, Guedes LU, Motta AR.Treinamento muscular na face: a prática dos fonoaudiólogos de Belo Horizonte. Rev Soc Bras Fonoaudiol. 2008;13(2):127-35

25. Zemlin WR. Princípios de anatomia e fisiologia em fonoaudiologia. 4 ed. Porto Alegre:Artmed; 2000.

26. Maio $M$, de Maio $M$, Domingos $M M$. Envelhecimento. In: Maio M. (Org.). Tratado de Medicina Estética. São Paulo: Roca Ltda; 2004;vol. 1. p. 249-266.

27. Jardini, RSR. Uso do exercitador facial: um estudo preliminar para fortalecer os músculos faciais. Pró-Fono R. Atual. Cient. Barueri. 2001;13(1): 83-9. 28. Lacourt MX, Marini LL. Decréscimo da função muscular decorrente do envelhecimento e a influência na qualidade de vida do idoso: uma revisão de literatura. RBCEH - Revista Brasileira de Ciências do Envelhecimento Humano. jan./jul. 2006;114-121.

29. Carvalho J, Soares JMC. Envelhecimento e força muscular - breve revisão Revista Portuguesa de Ciências do Desporto. 2004;4(3):79- 93

30. Rossi E. Envelhecimento do sistema osteoarticular. einstein. 2008; 6 (Supl 1):S7-S12.

31. BatistelaMA, ChorilliM, LeonardiGR.Abordagens no estudo do envelhecimento cutâneo em diferentes etnias. Rev. Bras. Farm. 2007;88(2): 59-62,

Endereço para correspondência:

Yasmin Frazão

Rua General Fonseca Teles, 551

CEP: 01433-020

E-mail: yasmin.frazao@terra.com.br 